\title{
CLÉRAMBAULT: O GOZO FEMININO
}

\section{Izabel Haddad Marques Massara \\ Jeferson Machado Pinto}

Resumo: $O$ texto apresenta casos clínicos atendidos na Enfermaria de Alienados de Paris pelo psiquiatra Gaëtan de Clérambault. As pacientes eram detidas pela polícia quando furtavam pedaços de seda em grandes lojas da cidade. No decorrer do acompanhamento clínico descobriu-se uma atração doentia das mesmas pela seda, e uma compulsão cleptomaníaca por furtá-las. $O$ estudo sistemático desses casos levou a formulação de uma hipótese diagnóstica: as pacientes apresentavam uma doença histérica cujo sintoma prevalente consistia em uma paixão arrebatadora por tecidos, utilizados para atingir o gozo sexual. $O$ esforço de sistematização desses casos clínicos levou o médico a escrever o livro, Paixão erótica pelos tecidos na mulher. A discussão romanceada das histórias das pacientes cleptomaníacas tornou-se um dos textos mais curiosos da literatura psiquiátrica. Esse artigo pretende, a partir dos casos das pacientes de Clérambault, apresentar reflexões a respeito do gozo feminino em Jacques Lacan.

Palavras-chave: Psicanálise. Psiquiatria. Mulheres. Prazer.

Diante do espanto dos senhores, devo estabelecer primeiramente uma analogia entre o criminoso e o histérico. Em ambos defrontamos com um segredo, alguma coisa oculta. Para não incorrer num paradoxo, devo em seguida apontar a diferença. O criminoso conhece e oculta esse segredo, enquanto o histérico não conhece esse segredo, que está oculto para ele mesmo. (Freud, 1906/1987, p. 109) 
Apsicanálise ampliao campo das indicações de um tratamento possivel do criminoso como tal - evidenciando a existência de crimes que só têm sentido se compreendidos numa estrutura fechada da subjetividade. (Lacan, 1966/1998, p. 131)

Em Paixão erótica da mulher pelos tecidos, escrito em 1908, o médico e psiquiatra Gaëtan Gatian de Clérambault, relata três casos clínicos de algumas pacientes atendidas por ele na enfermaria de uma delegacia e a relação de afeto particularmente curiosa das mesmas com as sedas e os veludos. $O$ texto apresenta o acompanhamento e a observação desses casos pelo médico, assinalando alguns pontos sobre a problemática e as repercussões psíquicas da relação das mulheres com esse objeto, o tecido, e com o gozo sexual experimentado por elas em decorrência do roubo do mesmo nas lojas de tecidos de Paris. O livro originado da compilação dos casos clínicos das pacientes de Clérambault é pouco conhecido e relata a curiosa história da reincidência das detenções dessas mulheres na delegacia da cidade de Paris. A fonte de maior relevância desses casos, segundo o próprio autor, é a paixão arrebatadora das mulheres pelas sedas e o curioso gozo sexual experimentado por elas em relação às peças de tecidos.

Clérambault foi um importante psiquiatra francês que passou parte de sua vida trabalhando na enfermaria de uma delegacia. Foi como mestre e professor de psiquiatria de Lacan que ele deu início aos estudos da topologia do inconsciente, tema que, posteriormente viria a dar origem a alguns textos da obra lacaniana. Os artigos compilados ganharam posteriormente o título sugestivo do livro que acabamos de citar e foram publicados entre 1908 e 1910, em uma revista especializada em artigos de antropologia criminal. A tentativa de encaminhar esses casos para uma discussão puramente médica ou criminológica sobre os sintomas não foi profícua, já que não foi possível, naquela época, descobrir o que tornava os sintomas inclassificáveis do ponto de vista das categorias classificatórias da época.

A Primeira Guerra Mundial ainda não havia eclodido e enquanto Clérambault se juntava ao rol dos alienistas em Paris, Freud buscava desvendar o inconsciente em Vienna. Enquanto o criador da psicanálise descortinava os mecanismos inconscientes com a clínica das histéricas, G. G. de Clérambault, por meio de suas observações clínicas, descrevia em mais de treze mil certificados médico-legais, fenômenos elementares da psicose e outros mecanismos psíquicos que ele chamou de degenerescência e alienação mental, com a minúcia de um colecionador de espécies raras. Se as mulheres contribuíram relevantemente para o início da psicanálise, elas também intrigaram Clérambault com o delírio de ciúmes ou a erotomania e, inusitadamente, com um gozo arrebatador pelas sedas e veludos. A clínica feminina daquela época já anunciava certas particularidades que os médicos ainda eram incapazes de descrever, embora a psicanálise já esboçasse suas primeiras discussões sobre as mulheres. 
O presente artigo trata da história dessas três pacientes e de suas curiosidades eróticas, algo que intrigava Clérambault, e moviam os alienistas e médicos do início do século a produzir textos para os arquivos de criminologia. As ideias positivistas e a clínica das categorizações mentais fazem do livro desse psiquiatra um dos principais expoentes de um contexto em que o papel dos alienistas na elaboração de uma verdadeira criminologia científica era muito relevante. $O$ esforço de Clérambault em transformar os casos clínicos atendidos em uma delegacia em um livro, foi talvez o mesmo que levara os magistrados de sua época a produzirem muitos compêndios de psiquiatria criminal. Esses manuais de criminologia eram escritos na tentativa de classificar e diferenciar uma série de condutas, devido à angústia de não saber mais como punir ou alterar as chamadas "recidivas perversas" que chegavam até a clínica em meio às demandas jurídicas. A dificuldade do diagnóstico entre criminosos e pacientes psiquiátricos era um incômodo. Em relação a esse contexto, Lacan afirmou:

Busca-se uma solução numa formulação científica do problema, isto é, numa análise psiquiátrica do criminoso a que deve reportar-se, após examinar todas as medidas de prevenção contra o crime e de proteção contra sua recidiva, o que podemos designar como uma concepção sanitarista da penalogia. (Lacan, 1966/1998, p. 139)

Entretanto, para além de descortinar o crime em questão e analisar as formas de preveni-lo, o que mais intrigava no caso das pacientes cleptomaníacas de Clérambault era o fato de elas sentirem um gozo sexual com a prática do furto e da manipulação dos órgãos sexuais com o auxilio dos tecidos.

Embora a concepção sanitarista da criminologia, e mesmo da medicina, supusesse a resolução de muitos problemas enfrentados pelos cientistas da época, o efeito desse processo era visto como duvidoso. Além do equívoco científico e da perversidade ideológica, há uma evidente deficiência no tocante à supressão dos males sociais que esse processo pretendia reprimir. Nessa época, a evolução do castigo ainda guardava uma relação paralela com a da formação da prova do crime. Responsabilizar era de certa forma castigar. Mas, as pacientes, pelo contrário, pareciam procurar o castigo, já que não se preocupavam em esconder o ato criminoso que praticavam, mas sim obter o prazer produzido pelo roubo em si, e pelas próprias características das peças de roupa furtadas.

Nesse contexto, de penas e punições, o livro de Clérambault foi escrito num esforço de sistematizar os casos mais curiosos atendidos por ele, no período entre 1905 e 1934, sendo que, curiosamente, muitos deles tinham uma história comum. Algumas mulheres chegavam até a "Enfermaria Especial de Alienados" por terem cometido furtos de pequenos pedaços de seda em grandes lojas da cidade. O mais curioso e intrigante era que, em seus de- 
poimentos, as moças relatavam ao delegado que roubavam por prazer, pois a seda Ihes causava uma sensação tátil exacerbada, o que as levava com frequência ao gozo sexual. O médico por sua vez não sabia como responsabilizá-las pelos delitos. Seguem dois relatos das próprias pacientes:

Eu sinto um inchaço da garganta e desfaleço. Quando eu posso pegar o tecido, eu o amasso e isso me causa um aperto particular no estômago, em seguida, eu experimento uma espécie de gozo que para completamente minha respiração, me sinto embriagada, não posso me conter. (Clérambault, 1908/2007, p.459)

Mas o gozo é, sobretudo grande quando eu furto. Roubar a seda é delicioso; comprá-la não me daria nunca o mesmo prazer.Contra a tentação minha vontade nada pode fazer, quando eu furto é mais forte do que eu; aliás, eu não penso em mais nada, eu me sinto tomada vertiginosamente. (Clérambault, 1908/2007, p. 459)

O relato das pacientes é claro ao definir um sentimento de vertigem e embriaguês em relação aos tecidos roubados, como se algo as arrebatasse de tal forma que era impossível conter o ato criminoso do furto, já que roubar parecia fazer parte de uma cena, a qual elas se submetiam sem saber o por que. A estranheza desses atos levou o médico a sistematizar os casos, pois assim ele acreditava que conseguiria classificar os sintomas em comum, para com isso chegar a um diagnóstico que se aplicava a todas elas.

Depois de escutá-las, o psiquiatra era encarregado de dar a sentença nos prontuários e encaminhar ao delegado um laudo sobre a sanidade ou não dessas mulheres. Nesse contexto, configurava-se,já em 1908, uma cena de tensão em que constatamos o fosso que se abria entre o sujeito suposto da ciência médica e jurídica, objetivo e categórico e o sujeito da Psicanálise - o inconsciente - objeto que ocupa outro lugar que não se restringe às especificidades pretendidas pelas ciências. Sabe-se que, para a psicanálise, a descoberta do inconsciente foi, por natureza, um golpe narcísico sobre as leis irrefutáveis da ciência clássica. Além disso, as mulheres já gozavam de um lugar de enigma na teoria psicanalítica, já que, segundo Freud, elas, por serem teorizadas a partir da referência fálica, padeciam de uma fragilidade superegoica e de pouco senso de justiça. Para Lacan, a questão da mulher, principalmente em relação a seu gozo, levava a teoria desenvolver-se por caminhos tortuosos. É sobre esse desregramento feminino que os médicos da época se debruçavam, já que algo se mostrava para além do que o discurso da ciência podia regular.

Na tentativa de uma captura diagnóstica, Clérambault observava detidamente as pacientes e descrevia nos prontuários os sintomas e acometimentos psíquicos das mesmas. A sistematização dos casos o levou a uma categoria diagnóstica precisa: as três pacientes sofriam de uma degene- 
rescência mental e, por extensão, de uma histeria. Nos prontuários curiosamente podia-se ler: histérica, amoral, delinquente, paixão erótica pela seda, impulsos cleptomaníacos, furtos.

No texto Funções da psicanálise em criminologia, Lacan afirma que se um grande número de sujeitos, em seus delitos, exibições, furtos, difamações, encontra e busca um estímulo sexual, este, sejam quais forem os mecanismos que o causam, seja angústia ou mesmo sadismo, por exemplo, não podem ser descritos apenas como cometidos por um transbordamento dos instintos. Eles devem ser avaliados pelo efeito de algo recalcado que faz sua aparição nos automatismos de repetição, mais especificamente nos casos de recidiva. $O$ caso dessas histéricas demonstra com clareza os efeitos de uma afecção psíquica que reincide e as coloca diante de uma satisfação certamente pulsional:"As tendências do sujeito não deixam de mostrar deslizamentos ligados ao nível de sua satisfação" (Lacan, 1966/1998, p. 150). Ou seja, os furtos guardavam uma relação com o prazer experimentado por elas de burlar a lei e usurpar algo do outro. As moças não se contentavam em ganhar ou comprar as sedas, mas o prazer localizava-se exatamente no ato do furto. É possível que roubar algo do outro completasse o quebra-cabeças de uma cena em que elas se tornavam completamente submetidas à sensação que lhes arrebatava. Logo, roubar poderia ser umas das formas de cobrar algo que o Outro lhe devia. Essa hipótese pode ser reforçada pelo fato de não existir nenhuma fantasia associada ao objeto roubado. O que transparece, de fato, são o repúdio e a raiva em relação ao Outro, que é totalmente excluído da cena, a não ser por ser enganado pelas mulheres cleptomaníacas.

Segundo Lacan, ao escutar relatos do neurótico ou do perverso recebe-se uma confissão de um gozo desagregador que eles obtêm ao se perderem na imagem fascinante do ato que repetem, no caso aqui o furto. Pode-se perceber o poder das relações um tanto quanto ambíguas que o sujeito estabelece com a própria realidade, as pessoas e os objetos que $o$ cercam. $O$ próprio psiquiatra se perguntava se as pacientes em questão eram fetichistas ou histéricas, pois apresentavam sintomas que as classificavam em ambas as categorias.

Embora a realidade psíquica dessas mulheres tivesse traços fetichistas, Clérambault acabou por diagnosticá-las como neuróticas e histéricas e não como perversas ou psicóticas. Nisso reside o fato de que, diante dos relatos, ele, sem nunca ter se deparado com tal quadro antes, tenha ficado muito espantado ao perceber que elas não se encaixavam em nenhuma categoria diagnóstica. Talvez, somente um psicanalista atento às pistas do inconsciente compreenderia a incoerência dos traços que essas pacientes apresentavam - seu egocentrismo, seus atos passionais e a estranha satisfação cleptomaníaca, na qual podíamos perceber certas particularidades, e o fato delas se colocarem como encerradas em sua própria suficiência. 
Clérambault, certamente, não viria conhecer os textos de Lacan sobre o feminino e a criminologia, mas ao escrever seu livro, ele talvez já conhecesse alguns dos textos de Freud como, Estudos sobre a histeria de 1895 , Os três ensaios sobre a sexualidade de 1905 e principalmente o texto $A$ Psicanálise e a Determinação dos Fatos nos Processos Jurídicos de 1906. Mas os apontamentos freudianos não foram suficientes para que Clérambault deixasse de ser persuadido pelas histéricas cleptomaníacas do início do século. $O$ que ele parecia ignorar era que, no caso das recidivas cleptomaníacas de suas pacientes, havia algo da ordem do não dito, ou seja, apesar da simulação de uma cena repetida, o transtorno psíquico histérico não aparecia nem se desenvolvia, senão na presença de um espectador. As próprias pacientes colocam um acento sobre a questão do furto: "Roubar a seda é meu prazer. Meus filhos tentam inutilmente me curar, comprando para mim seda em quantidade. Se me dessem um corte de seda no momento mesmo em que eu vou roubá-lo, isso não me daria nenhuma felicidade, ao contrário, isso me impediria de senti-la" (Clérambault, 1908/2007, p.459). O contentamento com o furto acontece logo que a seda é subtraída de outrem, entretanto o gozo que se segue pode ser explicado, em parte, por fazer referencia a alguém de quem se rouba o tecido.

$O$ encantamento pelo ato do furto e a cena que acontece posteriormente, ou seja, o onanismo com os pedaços de seda, levou o psiquiatra a descrever os sintomas como referentes a uma espécie de fetichismo. Essas descrições tomaram como pano de fundo os estudos feitos sobre o fetichismo clássico apontado por Richard von Krafft-Ebing ${ }^{1}$. Ao longo de todo o texto, o autor faz uma interlocução com as conclusões apresentadas por Krafft-Ebing (1942) a respeito das perversões. Ele mesmo havia definido que o fetichismo era "o desvio do interesse sexual para algumas partes do corpo do parceiro, para alguma função fisiológica ou para peças de vestuário" (p. 35). Nota-se nessa definição a importância que é dada não só ao aspecto parcial do corpo, mas também à capacidade que as peças do vestuário têm de servir de elementos que aprisionam o desejo.

Embora se encontrassem descrições de fetichismo apenas no caso dos homens, Clérambault acreditava que as breves conclusões a que havia chegado, com seus estudos sobre essa peculiar relação entre essas mulheres e os tecidos, podiam ser colocadas, por afinidades diagnósticas, ao lado do fetichismo verdadeiro, apresentado pela literatura médica: "Os autores clássicos dizem unanimemente que o fetichismo ainda não foi constatado nas mulheres; essa afirmação seria inexata se fosse preciso ligar nossos casos ao fetichismo; e, se não os ligamos, seu lugar não será marcado em nenhuma parte" (Clérambault, 1908/2007, p. 451). Ou seja, as mulheres 
apresentavam uma histeria, mas com traços de uma perversão fetichista, ou seja, eram inclassificáveis.

O discurso positivista dos alienistas do século XIX sobre as perversões foi substituído pelo discurso jurídico e teológico na tentativa de poder regular e classificar o desconhecido das condutas que fugiam à norma, sendo por isso uma ameaça a sociedade. Na contramão dessa análise, de que havia sempre uma falta grave no desconhecido, Freud foi um dos primeiros a introduzir pela Psicanálise, desde 1905, uma ruptura epistemológica na pretensão do discurso científico de poder se apropriar completamente das doenças mentais. Ele acreditava que, para além dos sintomas e sinais, existia algo, em certa medida, incontornável, que nomeou de inconsciente.

A prática psiquiátrica na delegacia de polícia colocava Clérambault num lugar pouco cômodo, visto que os pacientes chegavam até ele animados por uma demanda jurídica causada por delitos cometidos. Por outro lado, cada um trazia uma história psíquica que não podia ser ignorada mesmo não fazendo sentido para o discurso da lei. Clérambault, apesar de escrever nos prontuários que as pacientes eram delinquentes e amorais, acreditava que elas apresentavam uma doença histérica e que eram incapazes de responder às mesmas punições dadas a criminosos comuns. Se Clérambault as tivesse escutado mais um pouco perceberia que elas denunciavam a explicação e a origem dos sintomas em suas próprias passagens ao ato. Algo na cena do crime remetia a uma conduta puramente imaginária.

A doença histérica e suas peculiaridades sintomáticas colocavam o médico diante de um gozo feminino impossível de circunscrever em suas análises semiológicas. Como dizia Clérambault em um trecho do livro:"Elas parecem um gourmet solitário que saboreia um vinho delicado" (Clérambault, 1908/2007, p. 450). Essa cena descrita pelas pacientes nos remete a relação do toxicômano com a droga. Essas mulheres se serviam do tecido e se desfaziam dele depois do gozar sem nenhum apego, mas em todas as cenas era preciso que ele fosse usurpado de alguém. Ou seja, o ato do furto era primordial para obter o prazer.

Uma das argumentações era a de que a seda adquiria para elas a característica de um talismã, apresentando um poder de encantamento a partir do momento em que o objeto exercia sua atração, não por si só, mas por uma carcterística agregada e contingente. As suas propriedades físicas eram vistas como atrativos sensoriais venerados, além do poder conferido ao objeto pelo ato do furto proibido pela lei. O frescor e a fineza da seda, bem como certo ciciar ou barulho próprio da fricção do tecido na pele arrebatavam as pacientes levando-as a furtar o que apenas conferia maior potência ao objeto. $O$ fenômeno de transferência, desconhecido por Clérambault, talvez tivesse facilitado o acesso do psiquiatra ao mundo dessas possíveis criminosas. $\mathrm{O}$ amor de transferência poderia ser a porta para compreender o que se passava com as pacientes. Segundo Lacan, ainda 
no texto Funções da psicanálise em criminologia: "A estrutura mórbida do crime ou dos delitos é evidente: o caráter forçado desses na execução, sua estereotipia quando se repetem ....a incompreensibilidades dos motivos, tudo confirma a coação por uma força a que o sujeito não pode resistir" (Lacan, 1966/1998, p. 133). Parece que o psiquiatra estava diante de uma força desconhecida por ele e pelas próprias pacientes, mas pouco foi descoberto sobre isso.

A questão que se apresentava para o psiquiatra apontava para uma dificuldade não só em relação ao diagnóstico das afecções apresentadas pelas pacientes, mas também pela dificuldade apresentada por seu papel de representar o cumprimento da lei naquele lugar. Ou seja, era sua a incumbência de afirmar, nos laudos encaminhados ao delegado, se elas eram loucas, e por isso inimputáveis, ou se deveriam ser presas e responsabilizadas pelos delitos que haviam cometido.

Um gozo sem limites aparecia em um lugar onde a lei deveria vigorar, e isso nos coloca várias perguntas. Em relação ao impasse apresentado pelo texto, acerca do papel do psiquiatra na delegacia e mesmo ao próprio gozo feminino inclassificável, podemos abordar três pontos importantes: a questão da inimputabilidade e da responsabilidade do sujeito no ato de furtar, a questão do gozo feminino em jogo na cena, e a posição do psiquiatra diante dos sintomas das pacientes.

A inimputabilidade acarreta uma série de repercussões tanto para quem profere a sentença bem como para o sujeito que a recebe. No caso das pacientes de Clérambault, nos parece que a doença histérica se beneficiava do ganho secundário dessa sentença. A cena histérica nos apresenta uma rede intrincada de peculiaridades que fazem sentido no momento em que se constata no prontuário a reincidência do ato de furtar (alguns prontuários apresentavam 22 recidivas). Talvez pudéssemos nos perguntar se voltar à delegacia ao serem flagradas; e terem que falar disso repetidas vezes ao médico, fosse o que elas realmente desejavam sem saber, ou seja, elas repetiam os furtos para serem pegas. A repetição acontece como uma forma de simbolizar algo pulsional que não encontra caminho senão nas recidivas?

O gozo sexual experimentado por elas também nos remete ao que a psicanálise freudiana buscou todo tempo circunscrever a partir do caso dos homens. Freud apresenta no texto A psicanálise e a determinação dos fatos nos processos jurídicos sua conclusão em relação às enfermidades como as apresentadas pelas pacientes de Clérambault:

Ora, através de laboriosas pesquisas, sabemos que todas essas enfermidades resultam do êxito obtido pelo paciente na repressão de certas ideias e lembranças fortemente catexizadas com afeto, assim como dos desejos que delas se originam, de tal modo que não representam qualquer papel em seu pensamento, isto é, não penetram em sua consciência, permanecendo assim desconhecidos para ele. É 
desse material psíquico reprimido (desses 'complexos') que derivam os sintomas somáticos e psíquicos que atormentam o paciente, da mesma forma que uma consciência culpada. Nesse aspecto, portanto, é fundamental a diferença entre o criminoso e o histérico. (Freud, 1906/1987, p. 112)

A breve conclusão a que ele chega revela o que já podíamos deduzir dos relatos das pacientes: de que, na verdade, elas não sabiam o porquê dos sintomas cleptomaníacos, sendo o material psíquico subjacente totalmente desconhecido para elas mesmas. Toda a cena do furto, até o momento do gozo sexual, demonstra uma forma fixada de obter o prazer. E fica clara a implicação do objeto roubado com a deflagração do gozo, pois algumas das pacientes relatam que o barulho e a maciez da seda são imprescindíveis. Sabemos que a questão do gozo feminino permanece um tema espinhoso, mesmo e sobretudo, para a psicanálise. Lacan, em uma releitura da pulsão freudiana, nomeou o gozo feminino de seis formas diferentes no Seminário Mais ainda: gozo Outro, gozo do corpo, gozo suplementar, gozo feminino, gozo vaginal, gozo da mulher. O deslizamento que essa série de nomes atesta já nos coloca diante da dificuldade enfrentada pela psicanálise para descrever a mulher, já que ela não pode ser toda escrita pela linguagem.

Outro ponto importante dessa história parece ser protagonizado pelo próprio Clérambault. O médico psiquiatra, em seu esforço para sistematizar sintomas e classificá-los nosologicamente, postura que pode ser justificada pela peculiaridade de sua função, perdeu de vista a história que cada uma delas trazia, acompanhando a série de fatos incompreensíveis que as levava até a delegacia. Era preciso que ele escutasse, o que a psicanálise se esforçou para fazê-lo - o não dito por trás do dito, as repetições movidas pela força da pulsão e as pistas e resquícios do inconsciente deixados ao alcance do analista. Pois, a prova de que as coisas não se passavam bem como elas diziam, era que toda a cena deveria ser assistida pelo Outro, não bastava que elas estivessem a sós. Elas eram especialistas em furtar, mas também em serem vistas e pegas pelo furto. Tais condições de gozo denunciam o lugar do Outro para o sujeito e denotam a peculiaridade dessa relação nos casos relatados. Pode ser que a análise exaustiva das manifestações inconscientes não fosse uma preocupação de Clérambault, talvez pela incipiência da psicanálise ou das limitações de seu trabalho. Como já foi dito, seu objetivo de conhecer os sintomas e sinais das doenças era estritamente científico e circunscrito por sua função em criminologia.

Para a psicanálise, a realidade psíquica tem razões desconhecidas para o paciente, e demonstra algo que se traveste sempre com outra roupagem. Na verdade, a mola da transferência, ao reconhecer o lugar do Outro para o sujeito, poderia dar ao médico acesso ao mundo imaginário das pacientes, mas ele não reconheceu esse potencial em sua relação com elas:"Criações imaginárias, álibis e simulações onde se sustenta à realidade 
alienada que caracteriza o sujeito" (Lacan, 1966/1998, p. 145). Não era à toa que suas fantasias, os álibis que encontravam para furtar e as simulações histéricas as colocavam no lugar de alienadas.

O texto de Clérambault permite a formulação de uma pergunta: a loucura dessas mulheres as levava muitas vezes a se esconder por trás da lei que as considerava incapazes? Ou seja, se a paciente não era condenada a pagar por seus delitos, ela era por outro lado condenada a repeti-los até que eles fizessem sentido para alguém ou para elas mesmas? Ao que parece, essas mulheres cometiam as infrações para que algo as fizesse parar. O sofrimento psíquico se deixava ver ali, onde a repetição era incessante. $\mathrm{Na}$ verdade, elas não eram punidas pela lei, pois não ficavam presas, mas por outro lado eram condenadas a não poder responder nunca por seus atos. Tornavam-se reféns de seu próprio gozo, ou seja, daquilo que nem mesmo para elas fazia sentido. Era preciso interpretar mais profundamente o sentido dos traços paradoxais pelos quais se configurava toda a cena do delito. Esses atos aparentemente descuidados e impensados eram menos um delito e mais os paradoxos a que os sintomas de uma psicopatologia estão sujeitos.

O último ponto a ser ressaltado trata da questão do gozo. No livro a palavra "gozo" aparece todo o tempo, dita pelas pacientes, escrita no prontuário pelo médico. As detentas de Clérambault usavam e abusavam do objeto que roubavam das lojas, para depois jogar fora. Entretanto, o ápice do gozo era o momento de furtar algo do Outro, ou de fazer algo proibido. Aprendemos com Lacan que o gozo feminino está muito além do gozo fálico masculino, e por isso mesmo se mostra como uma alteridade absoluta. Por isso a mulher foi chamada a responder na psicanálise lacaniana no lugar do Outro sexo, ou de Outro absoluto, onde só podemos encontrar a meia-verdade já que não há inscrição simbólica capaz de deslindar o ser da mulher. Talvez por isso, o esforço de Clérambault de dizer algo sobre o gozo das mulheres não tenha sido em vão, mas sua pretensão de explicitar totalmente o que acontecia com elas não tivesse mesmo uma resposta

Lacan, no seminário Mais ainda, apresenta o gozo como aquilo que faz barreiras ao nosso saber. É esta afirmação que pode dar, em parte, uma resposta para o desconhecido dos atos dessas mulheres. O gozo se coloca para a psicanálise como uma instância que não se deixa reduzir nem pelas leis do princípio do prazer, nem da auto-preservação. Haja vista que as muIheres visavam somente o furto e gozavam com isso, sem ao menos se preocupar com o que podia Ihes acontecer depois. Seus atos não se ligavam a um pensamento lógico, elas nem mesmo reconheciam a lei, simplesmente não pensavam nisso! Não existia uma explicação que conseguisse dizer por que elas cometiam repetidamente os mesmos furtos, e nem mesmo algo que pusesse fim a essas repetições. Nessas cenas histéricas elas roubavam as sedas e depois jogavam os pedaços em um lugar qualquer, como se estes não lhes servissem mais para nada. 
Os casos clínicos atendidos por Clérambault e a história de suas pacientes histéricas e cleptomaníacas ilustra de forma clara a dificuldade da discussão sobre o gozo feminino e os limites do mesmo diante do que a lei ou mesmo a teoria da psicanálise pode regular. O livro escrito por G. G. de Clérambault há mais de cem anos é um esforço de sistematizar o enigma desses casos e a tensão existente entre campos distintos: a medicina, o direito e à psicanálise.

Clérambault talvez tenha tentado em vão fazer com que a lei regulasse algo completamente contingente como o gozo dessas mulheres com os tecidos. Por um lado, as instituições têm como tarefa regular os atos do sujeito em sociedade. Mas, pelo que a psicanálise revela sobre o sujeito, este deve ser escutado a partir de outro lugar, onde a lei é a do inconsciente, e onde nenhuma prisão pode ser maior do que a do próprio sintoma. A confissão a que essas mulheres eram submetidas talvez representasse uma das verdades criminológicas, mas não a verdade que a psicanálise persegue, pois o sujeito não confessa aquilo que nem ele mesmo sabe.

A psicanálise lida com o sujeito do inconsciente, esse que de certa forma causa uma perturbação à lei e à norma, pois ele representa o desconhecido, o que aparece na contramão das ficções que pretendem regular o homem. Freud mesmo já havia chegado à conclusão de que as mulheres não podiam ser descritas pela ficção do Édipo. Se elas reconheciam de certa forma a incidência de seus atos e se mesmo assim foram capazes de repetir os furtos, podemos concluir, entre outras coisas, que nesses casos havia uma procura inconsciente pelo castigo? Com os esclarecimentos freudianos sobre o supereu aprendemos que o sujeito pode buscar um castigo para expiar sua culpa. Mas podemos perguntar também se os casos não ilustram como a vontade de gozo pode ser superior a qualquer instância moral, e mesmo se o supereu não estaria, de fato, impondo uma forma de satisfação acéfala?

Uma das preocupações da ciência é a busca da verdade, ou da percepção mais próxima possível de toda a complexidade dos fatos que se apresentam, procura que não é a mesma do sujeito da psicanálise. A Psicanálise auxilia na busca dessa verdade quando inclui a subjetividade, não deixando quem quer que seja alienado de sua própria história. As pacientes de Clérambault padeciam de certa alienação em relação aos atos que cometiam.

A ênfase do título do texto centenário de Clérambault recai sobre a palavra "paixão" não por acaso. Foi esse desregramento feminino que levou o médico a não saber ao certo o lugar para o qual a paixão delas apontava: depois de tornar públicas suas fantasias, o que essas mulheres queriam? Ser presas pelos furtos, consideradas loucas, ou sugerir com uma cena algo inconsciente que se escondia por "debaixo dos panos"? A dificuldade do médico era a de descobrir se os furtos eram cometidos por mulheres fetichistas e perversas, que sabiam bem o que estavam fazendo, ou se elas 
padeciam de uma neurose histérica que as deixava no desconhecimento de seus próprios atos? O texto de Freud é claro ao afirmar:"Já apontamos a diferença principal: no neurótico o segredo está oculto de sua própria consciência; no criminoso, o segredo está oculto apenas dos senhores. No primeiro existe uma autêntica ignorância, embora não em todos os sentidos, enquanto no último só existe uma simulação de ignorância" (Freud, 1906/1987, p. 112).

A descoberta do inconsciente nos coloca diante não da inconsciência, mas de uma energia psíquica que não é da ordem da objetividade, pois escapa, tropeça e falha, nos colocando diante de uma quebra radical na concepção de homem. A fissura que se impõe ao pensamento lógico, marcado pela existência da razão, aparece no momento em que essa ferramenta não alcança a dimensão do sujeito que pratica o ato de infração. Lacan acrescenta em relação a isso:"só o analista pode demonstrar, contrariando o sentimento comum, a alienação da realidade do criminoso, num caso em que o crime dá a ilusão de responder a seu contexto social" (Lacan, 1966/1998, p. 143).

Em 1908, a presença de um psiquiatra em uma delegacia que funcionava, talvez não por acaso, no subsolo do Palácio da Justiça de Paris, revelou-se como o ensaio para a aproximação entre ciência e razão de um lado e inconsciente de outro. Embora, até nossos dias, esse encontro ainda nos reserve muitas tensões, ele não deixa de ser a tentativa de apresentar um olhar diverso que faz avançar muitos outros aspectos.

A psicanálise nasceu dos impasses freudianos diante da clínica das histéricas e, desde então, analisar a questão da feminilidade por um viés que ultrapassa o da norma fálica é uma tarefa impossível. Pelo que parece, Clérambault encontrou não somente a presença travestida do inconsciente nos atos de suas pacientes, mas com a natureza incontornável do gozo feminino. $\mathrm{O}$ impasse entre o que se pode regular pela lei e o que é da ordem de um gozo irreconciliável com qualquer tentativa de circunscrição, nos leva a perguntar como diante do gozo feminino um psiquiatra do início do século poderia ter respondido. O título do seu livro nos coloca diante de uma resposta: a paixão das mulheres. Sem perder o rigor teórico, mas preservando o que de mais particular existe na teoria do feminino: 0 fenômeno da paixão exige mais uma lógica da contingência do que para o que pode ser dito a partir do necessário.

\title{
Clérambault: the feminine enjoyment
}

\begin{abstract}
This text is concerned based on the presentation of clinic cases in the Paris Infirmary for the Insane by the psychiatrist Gaëtan de Clérambault. The patients were detained by the police after they were caught shoplifting pieces of silk in department stores. During their clinic follow up, Clérambault noticed the existence
\end{abstract}


of a sickly attraction of the patients towards cloths and a kleptomaniac compulsion to steal them. The systematic study of such cases led him to formulate the diagnostic hypothesis that the patients presented the clinical picture of a hysteric disease which prevailing symptom consisted of a fascinating passion for cloths and their subsequent use to attain sexual enjoyment. In an effort to systematize these clinical cases, the doctor wrote the book Erotic passion of women for cloth. Our paper presents reflections about the passion of women for cloth and the specific nature of their enjoyment supported by the text written by Clérambault and by the Lacan's theory of feminility.

Keywords: Psychoanalysis. Psychiatry. Women. Pleasure.

\section{Cléramblaut: la jouissance feminin}

Résumé: Le texte présente des cas cliniques reçus à l'Infirmerie d'Aliénés de Paris par le psychiatre Gaëtan de Clérambault. Les patients étaient arrêtées par la police quand elles s'appropriaient des morceaux de soie dans de grands magasins de la ville.Pendant l'accompagnement clinique, on a découvert une attration maladive de ces dernières pour la soie, et une compulsion cleptomaniaque de s'en approprier. L'étude systématique de ces cas a mené à une hypothèse diagnostique: les patientes présentaient une maladie hystérique dont le symptôme prédominant devenait une passion incontrôlable pour des tissus, utilisés pour atteindre la jouissance sexuelle. L'effort de systématisation de ces cas cliniques a mené le médecin à écrire un livre, Passion érotique pour les tissus chez la femme. La discussion romanesque des histoires de patientes cleptomaniaques est devenue un des textes les plus curieux de la littérature psychiatrique. Cet article a l'intention, à partir des cas de Clérambault, de présenter des réflexions au sujet de la jouissance féminine chez Jacques Lacan.

Mots-clés: Psychanalyse. Psychiatrie. Femmes. Jouissance.

\section{Clérambault: le goce femenino}

Resumen: El texto presenta casos clínicos atendidos en la Enfermería de Alienados de París por el psiquiatra Gaëtan de Clérambault.Las pacientes eran detenidas por la policia cuando hurtaban pedazos de tela en grandes tiendas de la ciudad. En el transcurso del acompañamiento clínico se descubrió una atracción enfermiza de las mismas por la seda, y una compulsión cleptománica por hurtarlas. El estudio sistemático de esos casos llevó a la formulación de una hipótesis diagnóstica: las pacientes presentaban una enfermedad histérica cuyo síntoma dominante consistía en una pasión arrebatadora por telas utilizadas para el placer sexual. El trabajo de sistematización de esos casos clínicos, llevó a lo médico a escribir el libro, Pasión erótica por las telas en la mujer. La discución de las historias de las pacientes cleptómanas, se volvió uno de los textos mas curiosos de la literatura psiquiátrica. Ese artículo pretende, 
a partir de los casos de las pacientes de Clérambault, mostrar reflexiones respecto del goce en las mujeres, en Jacques Lacan.

Palabras-clave: Psicoanálises. Psiquiatria. Mujeres. Placer.

\section{Referências}

Clérambault, G. (2007). Passion érotique des étoffes chez la femme. Paris: Masson et Cie. (Trabalho original publicado em 1908)

Freud, S. (1987). A psicanálise e a determinação dos fatos nos processos jurídicos. Edição standard brasileira das obras psicológicas completas de Sigmund Freud (2a ed., Vol. 9) Rio de Janeiro: Imago. (Trabalho original publicado em 1906)

Krafft-Ebing, R. (1942). Psicopatia sexual. Buenos Aires: Progresso e Cultura.

Lacan, J. (1998). Funções da psicanálise em criminologia. In J. Lacan, Escritos (pp. 127151). Rio de Janeiro: Jorge Zahar. (Trabalho original publicado em 1966)

Izabel Haddad Marques Massara, Psicanalista, Especialista em Teoria Psicanalítica pela Universidade Federal de Minas Gerais, Mestre em Psicologia com ênfase em Estudos Psicanalíticos pela Universidade Federal de Minas Gerais e Doutoranda em Psicologia com ênfase em Estudos Psicanalíticos pela Universidade Federal de Minas Gerais. Endereço para correspondência: Av. Pinheiros, 895, Retiro as Pedras, CEP: 35460-000, Brumadinho, MG. Endereço eletrônico: izabelhaddad@hotmail.com

Jeferson Machado Pinto, Psicanalista, Doutor em Psicologia pela Universidade de São Paulo e Professor Associado da Universidade Federal de Minas Gerais. Endereço para correspondência: Rua Levindo Lopes 333, sala 410, Bairro Funcionários, CEP: 30140-911, Belo Horizonte, MG. Endereço Eletrônico: jefpinto@uai.com.br

Recebido em: 11/08/2009

Aceito em: 3/03/2010 